\title{
Taiwanese Registered Nurses' Reasons for Failure to Practice
}

\author{
Huei-Lan Chang ${ }^{1,2}$ and Chiou-Fen $\operatorname{Lin}^{3,4^{*}}$ \\ ${ }^{1}$ Doctoral Student/Supervisor, National Taipei University of Nursing and Health Sciences, Taiwan \\ ${ }^{2}$ National Taiwan University Hospital Hsin-Chu Branch, Taiwan \\ ${ }^{3}$ Associate Professor/Nursing Consultant, School of Nursing, National Taipei University of Nursing and Health Sciences, Taiwan \\ ${ }^{4}$ Department of Nursing, Shuang Ho Hospital, Taipei Medical University, Taiwan
}

\section{Abstract}

We examined the reasons why registered nurses do not practice nursing and the correlations between their characteristics and nonpractice factors. One hundred twelve 22-item, six-category questionnaires were completed. Nurses' main reasons for not practicing nursing were "salaries are not adjusted with workload changes," "insufficient staff or excessive staff reduction," and "salaries disproportionate to workload." Health departments and hospital administrators should adjust nurse-to-patient ratios, include on-leave coefficients in human resource considerations, and arrange part-time staff. The related advocacy could encourage recognition of nursing work and respect for the nursing image. Manual operations should be simplified and positive work environments maintained.and "social living" and build the chance of "independence from parents" through the use of respite care. This result points to the educative contribution of respite care to the development and independence of disabled children.

\section{Publication History:}

Received: December 27, 2015

Accepted: March 14, 2016

Published: March 16, 2016

\section{Keywords:}

Nurses not in practice, Nursing shortage, Registered nurses

\section{Introduction}

According to the Taiwanese National Union of Nurses Associations (TUNA), only $60.97 \%$ of licensed nurses in Taiwan currently practice. Therefore, the increase in the number of nonpracticing registered nurses has led to a severe staff shortage, with $9 \%$ of Taiwanese nursing positions unfilled [1]. This staff shortage is substantially higher than the $5 \%$ vacancy rate often quoted in the literature and is the primary reason for ward closures and reductions in bed availability in numerous hospitals [2]. A report published by the Ministry of Health and Welfare (MOHW) classified the reasons why licensed nurses chose not to practice into three categories: (a) personal factors such as health problems or lack of interest in work; (b) job-related factors such as rotating shifts, work stress, or lack of professional respect; and (c) organizational factors such as a heavy workloads caused by insufficient staffing, low pay, inadequate benefits, and a lack of opportunities for career advancement [1]. Therefore, this study explored the reasons why licensed nurses choose not to practice and provided specific suggestions for the amelioration of these reasons.

Nursing is a highly stressful profession in which nurses face emergency situations, interaction with patients who have various diseases, problematic interaction with patients' families, and working rotational shifts on a daily basis. Therefore, nurses are prone to health problems including insomnia, anxiety, and back pain [3]. These difficulties have been found to negatively affect mental and physical health, morale, willingness to work, work efficiency, family life, social support, and work satisfaction; in addition, increased work-related stress has been associated with low work satisfaction, poor mental and physical health, and a tendency to resign from work $[4,5]$.

The highly disproportionate nurse-to-patient ratios in Taiwanese medical institutions have resulted in increased nursing stress and turnover. In certain severe cases, this disproportionality has been shown to increase the average duration of patient hospitalization, comorbidities and patient mortality, and the occurrence of accidents [2].

In a 2010 study conducted by the TUNA and the 1111 Human Resource Bank, 1,072 questionnaires from the Survey of Nursing Workplace Investigation were completed. The results indicated that the three primary reasons for nurses' resignation included insufficient salary, benefits, and incentives (50.75\%); overwhelming workloads (44.78\%); and disruption to daily living routines (25.37\%). Further, $57.28 \%$ of nurses wished to pursue other careers [12].

\section{Methods}

The study was conducted over a 10-month period and used numerous research methods, which were performed in five stages. In Stage 1, a semi-structured questionnaire was constructed following a review of studies examining the reasons that nurses do not practice. In Stage 2, the semi-structured questionnaires were sent via mail to 83 nurses who were nursing school graduates between 2000 and 2010 and received either registered nurse or licensed practical nursing licenses but were not practicing at the time of the survey. Of these nurses, 51 had never joined the nursing profession and 32 had ceased nursing. Data from the returned questionnaires were compiled. In the third stage, 10 nurses who had never joined the profession and 10 who had ceased nursing were invited to attend focus group sessions (two separate sessions were held for each group) to discuss their reasons for choosing not to practice. In Stage 4, the results obtained from the focus groups were compiled, and an initial questionnaire was drafted using a 5-point scale, in which higher scores indicated stronger reasons for failure to practice. The reliability and validity of the questionnaire were also analyzed. In Stage 5, the questionnaire was distributed to a target sample population.

\section{Participants}

The sample population included 25,116 nurses who had left the nursing profession between 2001 and 2010; data for these nurses were taken from the TUNA database. The study used $\mathrm{G}^{*}$ Power software

"Corresponding Author: Dr. Chiou-Fen Lin School of Nursing, National Taipei University of Nursing and Health Sciences, No. 365, Ming-te Rd., Peitou District, Taipei City, Taiwan; E-mail: evalin@ntunhs.edu.tw

Citation: Chang HL, Lin CF (2016) Taiwanese Registered Nurses' Reasons for Failure to Practice. Int J Nurs Clin Pract 3: 176. doi: http://dx.doi. org/10.15344/2394-4978/2016/176

Copyright: () 2016 Chang et al. This is an open-access article distributed under the terms of the Creative Commons Attribution License, which permits unrestricted use, distribution, and reproduction in any medium, provided the original author and source are credited. 
Citation: Chang HL, Lin CF (2016) Taiwanese Registered Nurses' Reasons for Failure to Practice. Int J Nurs Clin Pract 3: 176. doi: http://dx.doi.org/10.15344/2394$4978 / 2016 / 176$

Page 2 of 5

with the following parameters: tail $(\mathrm{s})=$ two, effect size $\mathrm{d}=0.45$, $a$ $=.05$, and power of the test $=0.997$; the estimated sample size was calculated as 90 . Therefore, with an estimated return rate of $10 \%$, the target sample size was calculated as 900 . Using random sampling with the same geographical distribution as the master sample, 405 of 11,313, 257 of 7,169, 213 of 5,952, and 25 of 682 nurses were chosen from Northern, Southern, Central, and Eastern Taiwan, respectively. These nurses' details comprised the mailing list for the Questionnaire. One hundred twelve valid questionnaires were returned, yielding a return rate of $12.44 \%$

\section{Instruments}

The study instrument included the reasons why new nursing personnel leave the profession and strategies for improving nurses' working environments. Subsequent to conducting four focus group discussions with the nonpracticing licensed nurses, the questionnaire was drafted. This survey comprised 52 reasons for choosing not to practice nursing. To test the validity of the questionnaire, three c Demographealtheables ministration experts, human resource management experts, and nursing administration experts assessed the consistency and validity of the draft. Items that attained a content validity index of less than 0.7 were omitted. The resulting "Nonpracticing Reasons Survey" consisted of 22 reasons for choosing not to practice nursing. To assess the reliability of the survey, the questionnaire was e-mailed to 32 nonpracticing licensed nurses, and a reliability analysis was performed on the results. Cronbach's $\alpha$ was calculated at 0.974, signifying that the questionnaire items exhibited internal consistency.

\section{Ethical Considerations}

Participants who signed the informed consent form had the right to withdraw from participation at any time without their withdrawal affecting their rights.

\section{Data Analysis}

SPSS 15.0 for Windows (English version) was used to analyze the 18 returned questionnaires.

\section{Results}

\section{Demographics}

Women accounted for $98.2 \%$ of the respondents (Table 1). The majority of the respondents were aged between 31 and 40 years (46.8\%) and held a degree from a junior college (43.6\%). The ratio for single (47.7\%) to married (50.5\%) respondents was almost equal. In addition, the majority of the respondents were unemployed $(41.3 \%)$, had no children (53.6\%), did not provide care for family members (40.9\%), held registered nurses' licenses $(62.7 \%)$, received their first nursing degree between 2001 and 2005 (33.6\%), and had practiced nursing for one year or less (40.5\%).

\section{Reasons for Choosing Not to Practice}

Of the categories of nursing graduates' reasons for choosing not to practice (Table 2$)$, the score for salaries and benefits $\left(\mathrm{M}=\_4.23, \mathrm{SD}=\right.$ 1.03) was the highest, indicating that it was the most influential factor, followed by rotating shifts $(\mathrm{M}=3.98, \mathrm{SD}=1.22)$, work-related factors $(\mathrm{M}=3.84, \mathrm{SD}=1.12)$, training and career advancement $(\mathrm{M}=3.61, \mathrm{SD}$ $=1.22)$, interpersonal relations $(\mathrm{M}=3.15, \mathrm{SD}=1.28)$, and internship experience $(\mathrm{M}=2.58, \mathrm{SD}=1.09)$.

\begin{tabular}{|c|c|c|c|c|}
\hline Variables & $\mathrm{n}$ & $\%$ & Variables & $\mathrm{n}$ \\
\hline \multicolumn{3}{|l|}{ Sex } & \multicolumn{2}{|l|}{ Number of Children } \\
\hline Male & 2 & 1.8 & 0 & 59 \\
\hline Female & 108 & 98.2 & 1 & 18 \\
\hline No answer & 2 & & 2 & 26 \\
\hline Age & & & $\geq 3$ & 7 \\
\hline $21-30$ years & 42 & 37.8 & No answer & 2 \\
\hline $31-40$ years & 52 & 46.8 & $\begin{array}{l}\text { Number of Family } \\
\text { Members Requiring Care }\end{array}$ & \\
\hline $41-50$ years & 11 & 9.9 & 0 & 45 \\
\hline$>51$ years & 6 & 5.4 & 1 & 24 \\
\hline No answer & 1 & & 2 & 30 \\
\hline Nursing Education & & & $\geq 3$ & 11 \\
\hline Junior college & 48 & 43.6 & No answer & 2 \\
\hline $\begin{array}{l}\text { Two-year } \\
\text { technical college }\end{array}$ & 31 & 28.2 & Nursing License & \\
\hline $\begin{array}{l}\text { Four-year } \\
\text { technical college }\end{array}$ & 6 & 5.5 & Licensed practical nurse & 12 \\
\hline University & 21 & 19.1 & Registered nurse & 69 \\
\hline Graduate studies & 4 & 3.6 & Both & 29 \\
\hline No answer & 2 & $\begin{array}{l}\text { No } \\
\text { answer }\end{array}$ & 2 & \\
\hline \multicolumn{3}{|l|}{ Marital Status } & \multicolumn{2}{|c|}{ Date of First Nursing Degree } \\
\hline Single & 53 & 47.7 & Prior to 1971 & 1 \\
\hline Married & 56 & 50.5 & 1971-1975 & 1 \\
\hline $\begin{array}{l}\text { Divorced or } \\
\text { separated }\end{array}$ & 2 & 1.8 & $1976-1980$ & 5 \\
\hline No answer & 1 & 0.9 & 1981-1985 & 0 \\
\hline $\begin{array}{l}\text { Current } \\
\text { Occupation }\end{array}$ & & & 1986-1990 & 5 \\
\hline None & 45 & 41.3 & 1991-1995 & 12 \\
\hline Student & 8 & 7.3 & 1996-2000 & 21 \\
\hline Industry & 3 & 2.8 & 2001-2005 & 35 \\
\hline Business & 10 & 9.2 & $2006-2010$ & 21 \\
\hline Public servant & 5 & 4.6 & 2011 or later & 3 \\
\hline Other & 38 & 34.9 & No answer & \\
\hline \multirow[t]{9}{*}{ No answer } & 3 & & \multicolumn{2}{|l|}{$\begin{array}{l}\text { Number of Years of } \\
\text { Nonpractice }\end{array}$} \\
\hline & & & $\leq 1$ year & 43 \\
\hline & & & $1-3$ years & 17 \\
\hline & & & $4-6$ years & 18 \\
\hline & & & $7-9$ years & 12 \\
\hline & & & $10-12$ years & 9 \\
\hline & & & $13-15$ years & 2 \\
\hline & & & $\geq 16$ years & 5 \\
\hline & & & No answer & 6 \\
\hline
\end{tabular}

Table 1: Analysis of Basic Demographic Variables $(\mathrm{N}=112)$. 


\begin{tabular}{|c|c|c|}
\hline Salaries and Benefits & 4.23 & 1.03 \\
\hline Salaries disproportionate to workload & 4.41 & 0.99 \\
\hline Salaries do not increase with seniority & 4.10 & 1.09 \\
\hline $\begin{array}{l}\text { Salaries are not adjusted with changes in } \\
\text { position }\end{array}$ & 3.70 & 1.21 \\
\hline $\begin{array}{l}\text { Salaries are not adjusted with changes in } \\
\text { workload }\end{array}$ & 4.55 & 0.82 \\
\hline $\begin{array}{l}\text { Overtime rates of } 1.33 \text { or } 1.66 \text { times the } \\
\text { normal rate are not provided in accordance } \\
\text { with basic labor laws }\end{array}$ & 4.41 & 1.05 \\
\hline Interpersonal Relationships & 3.15 & 1.28 \\
\hline $\begin{array}{l}\text { Poor communication between nursing } \\
\text { administrators and nurses }\end{array}$ & 3.29 & 1.22 \\
\hline Poor relationship with nursing supervisor & 3.01 & 1.37 \\
\hline $\begin{array}{l}\text { Poor communication with doctors or feel } \\
\text { disrespected by doctors }\end{array}$ & 3.16 & 1.25 \\
\hline Nature of the Work & 3.84 & 1.12 \\
\hline $\begin{array}{l}\text { Insufficient staffing or excessive reduction in } \\
\text { staffing }\end{array}$ & 4.53 & 0.83 \\
\hline Difficulty scheduling vacation time & 3.92 & 1.18 \\
\hline Often late leaving work & 4.17 & 1.10 \\
\hline The work is harmful to my health & 4.21 & 1.09 \\
\hline $\begin{array}{l}\text { The mental stress of dealing with patient } \\
\text { suffering or death is too great }\end{array}$ & 3.41 & 1.20 \\
\hline I am not interested in nursing & 2.81 & 1.30 \\
\hline Rotating Shifts & 3.98 & 1.22 \\
\hline $\begin{array}{l}\text { Rotating shifts make it difficult to balance } \\
\text { work and family life }\end{array}$ & 4.24 & 1.16 \\
\hline Rotating shifts cause social difficulties & 3.65 & 1.24 \\
\hline $\begin{array}{l}\text { Rotating shifts have a serious negative effect } \\
\text { on sleep }\end{array}$ & 4.06 & 1.25 \\
\hline Internship Experience & 2.58 & 1.09 \\
\hline $\begin{array}{l}\text { Did not receive adequate support or } \\
\text { guidance during the internship period }\end{array}$ & 2.56 & 1.06 \\
\hline $\begin{array}{l}\text { I am not confident that I can undertake } \\
\text { clinical responsibilities }\end{array}$ & 2.60 & 1.12 \\
\hline Training and Career Advancement & 3.61 & 1.22 \\
\hline $\begin{array}{l}\text { Rotating shifts make it difficult to schedule } \\
\text { continuing education or training }\end{array}$ & 3.61 & 1.20 \\
\hline $\begin{array}{l}\text { Too few opportunities to attain advanced } \\
\text { degrees while working }\end{array}$ & 3.38 & 1.23 \\
\hline $\begin{array}{l}\text { Too few avenues or opportunities for career } \\
\text { advancement }\end{array}$ & 3.85 & 1.23 \\
\hline
\end{tabular}

Of the specific reasons for choosing not to practice, the score for "salaries are not adjusted with changes in workload" was the highest $(\mathrm{M}$ $=4.55, \mathrm{SD}=0.82)$, indicating that this was the most influential reason, followed by "insufficient staffing or excessive staffing reduction" (M $=4.53, \mathrm{SD}=0.83$ ), and "salaries are disproportionate to workloads" $(\mathrm{M}=4.41, \mathrm{SD}=0.99)$. The three least influential factors were "did not receive adequate support or guidance during the internship period" $(\mathrm{M}=2.56, \mathrm{SD}=1.06)$, "I am not confident that I can take on clinical responsibilities" $(\mathrm{M}=2.60, \mathrm{SD}=1.12)$, and "I am not interested in nursing" $(\mathrm{M}=2.81, \mathrm{SD}=1.30)$.

\section{Discussion}

The results of this study revealed that, of the six major categories of reasons for choosing not to practice, the three primary categories identified were salaries and benefits, rotating shifts, and work-related factors. Regarding specific reasons within these categories, the highest scoring item was "salaries are not adjusted with changes in workload," followed by "insufficient staffing or excessive staffing reduction." These results corroborate those of Chang, Lu, and Lin [13] and the 2010 Nursing Workplace Status Survey conducted by the TUNA in conjunction with the 1111 Human Resource Bank. Chang et al. [14] found that nurse' primary reasons for choosing to leave the profession involved work-related factors such as overwhelming work stress, increased workload, unbalanced nurse-to-patient ratios, late shifts, and overwhelming allocation of tasks or responsibilities.

In a study examining resignation prediction factors, high salary was correlated with low resignation intention [15], and a Finnish study reported that dissatisfaction with salary compensation was the primary reason for resignation for 147 registered nurses [16]. In another study conducted by Lin, Wu, Liu, and Lin [17], shift work was a predictive factor for resignation in 988 registered nurses. These results are also congruent with those of a study conducted by [18], in which unsatisfactory working conditions were the primary reason that 134 registered nurses chose not to practice.

In the Localized Nursing Retention Strategy Model study, commissioned by the MOHW [2], eight major dimensions, including training new nursing personnel and assisting new nurses in adjusting to their working environments, were identified. Primary nursing was previously believed to be the optimal nursing model; however, because of the current nursing shortage and inadequate preparation of new nurses, allowing recent nursing graduates to assume the responsibilities of primary nurses poses certain difficulties. Therefore, a new model integrating primary nursing with team and functional nursing may facilitate new nurses' implementation of functional tasks and allow them to familiarize themselves with their tasks before performing additional work. Previous research has indicated that nurses typically dislike the amount of paperwork they are required to complete. Therefore, developing various electronic nursing records using information systems reduces the amount of time spent completing documentation and increases work efficiency [14]. Furthermore, other methods, such as forming support groups, improving human resource arrangements, implementing career planning and resignation reduction programs, and creating healthy workplaces, can increase nursing professionalism and reduce nurses' intention to resign.

Our findings indicated that the primary reason for nursing graduates' failure to practice nursing was insufficient staffing or an excessive reduction in staffing. A reasonable nurse-to-patient ratio can improve patient safety and reduce the occurrence of accidents. However, this ratio should be adjusted according to the situation; for example, increases in the number of nurses employed may be required due to patient dependence [19]. The current standard nurse-to-patient ratio in Taiwanese medical institutions is set by the Taiwan Joint Commission on Hospital Accreditation, where a nurse-to-patient ratio of 1:10 is required during the day shift, with no specific requirements for the late or graveyard shifts; this nurseto-patient ratio is approximately 2.0-2.5 times higher than those of other developed countries, which indicates that the Taiwanese ratio is severely disproportional [12]. The Taiwan National Health Research Institutes reported that most nursing supervisors estimated the ideal 
number of nursing hours for a regular ward at 2.0-4.1 per patient per day and believed that this should be increased to a minimum of 3.6 per patient per day within 5 years [20].

In 2013, the MOHW suggested reducing the comprehensive general acute hospital ward staffing standard ratio of one nurse to four beds to that of one nurse to three beds [2]. The standards were set to achieve nurse-to-patient ratios similar to those of Japan (1:7 for all three shifts), the United States, and Australia (1:4-5 for the day shift, 1:4-6 for the late shift, and 1:8-10 for the graveyard shift). The simplification of nursing records and digitalization of nursing information could also be beneficial in reducing the number of nonpracticing nurses. Further, hospitals should consider hiring parttime nurses with 7-8 years of experience, to reduce peak-hour staff shortages by performing procedures such as medication and injection administration. Hospitals employing part-time personnel could effectively reduce workloads and address problems such as delayed shifts, staff shortages, and difficulties balancing family and shift work. Workload reductions could also solve problems related to reasons for choosing to resign such as "salaries are not adjusted with changes in workload" and "salaries are disproportionate to workload." Chang et al. (2010) found that nursing personnel were least satisfied with "reasonable salary and benefits" and "reasonable human resource allocation and appropriate work arrangements."

In our study, nonpracticing registered nurses were aged 31-40 years, and $46.8 \%$ were unemployed, suggesting that they would rather be unemployed than return to nursing. The other group of nonpracticing registered nurses consists of nurse specialists (of whom there are approximately 10,000 in Taiwan); other nonpracticing registered nurses have become flight attendants and medical equipment salespersons. The associated authorities should consider incentives to encourage nonpracticing registered nurses to return to the profession. Government officials and administrators should focus on the severity of the nursing shortage. Our results indicated that, for both practicing and nonpracticing nurses, problems involving staffing and salaries and benefits are indicators that should be used in the assessment of nursing work. However, to solve these problems, the healthcare system must be improved. Future hospital evaluation systems could include amendment of nurse-to-patient ratios and improvements in salary adjustment systems. Changes in hospital policy are also crucial to improving salary and benefits and human resource allocation. Hospital infrastructures should also use proper information technology systems in simplifying manual operations and maintaining a positive work environment.

\section{Study Limitations}

A total of 900 questionnaires were distributed; however, only $12.44 \%$ of these were returned complete. Therefore, we suggest that future studies increase the number of questionnaires distributed.

\section{Conclusion}

Our study indicated that, of the six categories of reasons for failure to practice, the top three were salaries and benefits, rotating shifts, and work-related factors. Regarding specific reasons within these categories, the highest scoring item was "salaries are not adjusted with changes in workload, insufficient staffing, or excessive staffing reduction," followed by "insufficient staffing or excessive staffing reduction." Based on our results, we recommend that the health departments and hospital administrators focus on nurse-to-patient ratios, include on-leave coefficients when determining appropriate human resource considerations, and arrange for part-time staff to reduce peak-hour staff shortages. Public advocacy and awareness of nursing-related professions should also be used to promote nurses as positive and respected role models. In addition, hospital infrastructures should use appropriate information technology systems to simplify manual operations and maintain positive working environments.

\section{Competing Interests}

The authors have no competing interests with the work presented in this study.

\section{Funding}

This study was funded by the Ministry of Health and Welfare, Executive Yuan of Taiwan (DOH101-TD-M-113-101005).

\section{References}

1. Chiu WT (2012) How to improve nursing practice environment, to solve the shortage of nurses and maintaining patient safety. The National Union of Nurses Associations (TUNA)Magazine, 86: 1-5.

2. Lin CF, Huang HY, Lu MS (2013) The development of nursing workforce allocation standards for acute care general wards in Taiwan. J Nurs Res 21: 298-306.

3. Kemper K, Bulla S, Krueger D, Ott MJ, McCool JA, et al. (2011) Nurses' experiences, expectations, and preferences for mind-body practices to reduce stress. BMC Complement Altern Med 11: 26.

4. Barnard D, Street A, Love AW (2006) Relationships between stressors, work support, and burnout among cancer nurses. Cancer Nurs 29: 338344.

5. Liu YH, Liu WW (2009) Exploring relationships among emotional labor, job stress, and coping behaviors in nurses. The Journal of Health Sciences 11: $98-115$

6. Chen $\mathrm{KH}$, Chen LH, Su S (2006) Exploring the attitudes of nursing staffs toward job perception and turnover intention. Taiwan Journal of Public Health 253: 177-188.

7. Chen LF, Chu TW, Chou CC (2005) Study of the career stress, job satisfactions, and turnover tendency of clinical obstetric, gynecological and pediatric nurses in a medical center. Chang Gung Nursing 16: 264-273.

8. Lu KY, Lin PL, Wu CM, Hsieh YL, Chang YY (2002) The relationships among turnover intentions, professional commitment, and job satisfaction of hospital nurses. Journal Professional Nursing 18: 214-219.

9. Duffield C, Pallas LO, Aitken LM (2004) Nurses who work outside nursing. J Adv Nurs 47: 664-671.

10. Fochsen, G., Sjogren, K., Josephson, M., \& Lagerström, M. (2005) Factors contributing to the decision to leave nursing care: A study among Swedish nursing personnel. J Nurs Manag 13: 338-344.

11. Halfer D, Graf E (2006) Graduate nurse perceptions of the work experience. Nurs Econ 24: 150-155, 123.

12. The prevalence of work among nurses (2010) The Taiwanese National Union of Nurses Associations (TUNA) Magazine 76: 2-3.

13. Chang HL, Lu MS, Lin CF (2010) Factors related to new nursing staff turnover rates. Journal of Health Science 12: 161-172.

14. Chang HF, Lin YH, Wang SM, Jao YH, Wu HP (2010) The study of healthcare workers' job stress sources and intention to leave. Cheng Vhing Medical Journal 6: 21-31.

15. Borkowski N, Amann R, Song SH, Weiss C (2007) Nurses' intent to leave the profession: Issues related to gender, ethnicity, and educational level. Health Care Management Review 32: 160-167.

16. Flinkman M, Laine M, Leino-Kilpi H, Hasselhorn HM, Salanterä S (2008) Explaining young registered Finnish nurses' intention to leave the profession: A questionnaire survey. International J Nurs Stud 45: 727-739.

17. Lin MC, Wu LC, Liu CC, Lin SY (2010) Comparisons of organization commitments and intention to leave in different job position of nurses. The Kaohsiung Journal of Nursing 27: 1-12. 
Citation: Chang HL, Lin CF (2016) Taiwanese Registered Nurses' Reasons for Failure to Practice. Int J Nurs Clin Pract 3: 176. doi: http://dx.doi.org/10.15344/23944978/2016/176

Page 5 of 5

18. Gök AU, Kocaman G (2011) Reasons for leaving nursing: a study among Turkish nurses. Contemp Nurse 39: 65-74.

19. Jones G, Kettles A, Spurrier A (2009) A staffing ratio customised to meet patient needs can be a flexible friend. Nursing Standard 23: 32

20. Zhang M, Yu YM (2010) Nurse Workforce \& Nurse Practitioner System Vision and Challenges. Taiwan, R.O.C.: National Health Research Institutes 